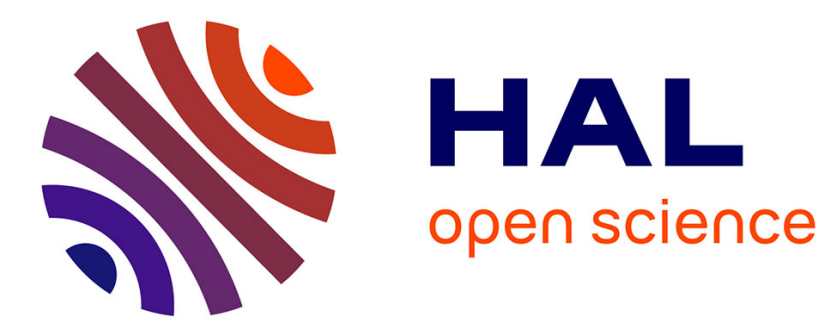

\title{
The rhetoric of conference presentation introductions : context, argument and interaction
}

\author{
Elizabeth Rowley-Jolivet, Shirley Carter-Thomas
}

\section{To cite this version:}

Elizabeth Rowley-Jolivet, Shirley Carter-Thomas. The rhetoric of conference presentation introductions : context, argument and interaction. International Journal of Applied Linguistics, 2005, 15 (1), pp.45-70. 10.1111/j.1473-4192.2005.00080.x . hal-00275963v2

\section{HAL Id: hal-00275963 \\ https://shs.hal.science/hal-00275963v2}

Submitted on 27 Jun 2008

HAL is a multi-disciplinary open access archive for the deposit and dissemination of scientific research documents, whether they are published or not. The documents may come from teaching and research institutions in France or abroad, or from public or private research centers.
L'archive ouverte pluridisciplinaire HAL, est destinée au dépôt et à la diffusion de documents scientifiques de niveau recherche, publiés ou non, émanant des établissements d'enseignement et de recherche français ou étrangers, des laboratoires publics ou privés. 
Pre-print version

The definitive version is available at www.blackwell-synergy.com

\section{The Rhetoric of Conference Presentation Introductions Context, Argument and Interaction}

Elizabeth Rowley-Jolivet

Ecole Polytechnique de l'Université

d'Orléans,

Site Galilée

12 rue de Blois,

BP 6744

45067 Orléans

France

Elizabeth.Jolivet@univ-orleans.fr

Fax: + 33238417377
Shirley Carter-Thomas

Institut National des Télécommunications

(GET/INT),

Département Langues et Sciences

Humaines,

9 rue Charles Fourier,

91011 Evry,

France

Shirley.Thomas@int-evry.fr 


\title{
The Rhetoric of Conference Presentation Introductions Context, Argument and Interaction
}

\begin{abstract}
The process of socialisation into the academic discourse community involves acquiring mastery of its established genres. While written academic genres have been intensively studied, spoken genres - despite their important role in the initiation of novices - are relatively underresearched. This study focuses on one such spoken research genre, the scientific conference presentation (CP) in English, and specifically on the introduction section, a sub-genre which often poses particular problems for presenters. Through a move analysis of the introductions, we show that their rhetorical structure is markedly different from that of the research article, and relate the move categories identified to the contextual and epistemological characteristics of the genre. A second rhetorical aspect addressed concerns the interpersonal relations set up by the allocation of speaker and addressee roles through the use of personal pronouns. By a contrastive analysis of CP introductions and those of the corresponding proceedings articles, we examine how speakers facilitate information processing and create rapport with the audience. The data comprise video recordings of 44 conference presentations from 3 scientific fields (geology, medicine, and physics) and a smaller parallel corpus of 13 articles from the proceedings in physics.
\end{abstract}

\section{Introduction}

One of the key spoken genres that the academic researcher needs to master is the conference presentation (CP). Conferences play an essential role in the life of research communities, and the conference presentation fulfils distinctive functions in claimmaking and in marking out a research territory (Rowley-Jolivet 2002). By analysing how language is used in this communicative situation and heightening awareness of its specific and contextually-motivated features, applied linguistics has an important role to play in helping scientific researchers participate more effectively in the discourse practices of their field. For all researchers, whatever their native origin, proficiency in academic genres is an acquired, or learned, skill, and while these genres are not a rigid mould - they are sufficiently flexible to allow language- or culture-specific variations, or even deliberate flouting of the conventions - the contextual constraints of a particular communicative event, as well as specific disciplinary needs, will tend to exert a normalising influence, leading to convergence on a fairly stable configuration of features. This is clearly the case in the research article, where a high degree of conformity to academic discourse norms is required. It is perhaps less immediately obvious that the more institutionalised forms of academic speech, such as thesis defences, conference presentations, and departmental colloquia, also need to be acquired and that they may bear little resemblance to everyday talk or conversational exchanges. Much of the socialisation of novice academics into their discourse community is achieved through talk for, as Mauranen points out, a great deal of 
academic communication takes place in speech, not in writing, through seminars, lectures, conferences, and other forms of academic oracy (2001:165). Until recently, however, scant attention has been paid to the analysis of the characteristic features of academic speech, partly perhaps because of its less prestigious epistemological status but also more mundanely because of the greater difficulty of accessing and deconstructing oral corpora ${ }^{\mathrm{i}}$.

Written academic discourse, on the other hand, has been intensively studied over the last 20 years, in particular the research article (RA), "that master narrative of our time" (Swales 2003, quoting Montgomery 1996). Though the genre is still arguably under-speciated, the picture we have is increasingly complete, thanks to diachronic studies of its emergence and evolution (Bazerman 1998; Atkinson 1999; Valle 1999), genre-based analyses of rhetorical structure (Swales 1990), and monographs on specific features such as evaluation (Hunston 1989) or hedging (Hyland 1998). Among the various sections of the RA, the introduction has attracted the most attention, not only because of its important rhetorical role in positioning the research and establishing the credibility of the author, but also because of its concomitant difficulties:

The introduction section is a particularly crucial subgenre in that the writing of introductions is for most, if not all of us, a major rhetorical hurdle. Novice researchers and those forced to publish in languages other than their own can find it even more daunting. (Burgess 2002:198)

The introduction to the conference presentation we contend can pose an even greater problem for novice researchers than that of the RA. The relative lack of interest in spoken academic genres means that there is a corresponding shortage of material available for deconstruction and genre-based teaching methodologies. Unlike in the case of the RA, there are also no gatekeeping processes or formal criteria to guide scientists unfamiliar with either the genre or the appropriate English language and to enable them to hone their rhetorical skills. Conference presentation proposals are accepted by the scientific committee of the conference on the basis of the informational content alone, and not on the appropriacy of the oral presentation itself to the contextual constraints of the genre or on the communicative proficiency of the speaker. Acquiring the requisite "situated cognition" (Berkenkotter \& Huckin 1995:3) which will enable speakers, by the strategic deployment of genre knowledge, to find their own voice in communicative contexts very different from the RA, is therefore problematic. 
In addition to mastering the genre, presenters need to master the linguistic code which, at international scientific conferences nowadays, is almost exclusively English. As recent corpus-based grammars of writing and speech (Biber et al. 1999) have clearly shown, different forms of spoken English - conversation, lectures, news broadcasts display marked, and distinct, regularities in their use of the English language. Recasting the research in an oral genre such as the $\mathrm{CP}$, therefore, calls not only on awareness of the spoken register in which meaning partly resides in the exophoric communicative context, but also on familiarity with the appropriate form of talk and role relationships. Presenters thus face the dilemma of displaying the requisite interpersonal and pragmatic competence of face-to-face communication between peers (Tracy 1997). The opening stage of the conference presentation is in particular the locus of complex pragmatic choices where "the discourse community member's ability to make situationally appropriate responses" (Shalom 2002:61) is put to the test.

In this article we will therefore focus on the introductory sections in conference presentations, to investigate how native English-speaker scientists respond rhetorically to this context. Our aim in selecting this specific group of speakers is not to hold them up as model to which all other non-native speakers are expected to conform. International scientific conferences form a highly intercultural setting, where ELF interaction takes place among a wide range of speakers of different linguistic and cultural origins. By concentrating however in an initial stage on this linguistically homogeneous group we hope to be able to pinpoint more closely the substantial differences induced by the contextual and cognitive features of the CP genre in relation to its written counterpart - features which speakers of all nationalities need to discoursally manage when delivering a conference presentation. Such an analysis is a necessary prerequisite to any further analysis involving the investigation of possible cultural and linguistic variables.

The study will examine two aspects of the CP introduction that recent work on professional and academic discourse undertaken from a rhetorical perspective has isolated as being of particular importance, namely the inherently suasive and interactive nature of this discourse, and the contextually situated dimension of argument (Freedman \& Medway 1994). A powerful tool for exploring a discourse's argumentative structure or internal organisation is move analysis (Swales 1981; 1990). Move analysis has not however to the best of our knowledge been previously applied to the conference presentation genre. With the exception of S. Thompson's (1994) analysis of university 
lectures, most move-based analyses have in fact been devoted to various written academic discourse genres. As several studies have shown however, there are numerous factors of variation that impact on move structure - such as the discipline or field (Samraj 2002; Crookes 1986), the nature of the audience (Nwogu 1997; S. Thompson 1994), the section of the genre (Dudley-Evans 1994) and the cultural or linguistic background of the text producer (e.g. Cmerjkova 1996; Taylor \& Chen 1991). In the first part of this article we will focus on other factors of variation directly linked to the spoken mode of delivery and the scientific conference setting. Through a comparison between our data and existing models, we will try to bring out the recurrent rhetorical features of the CP introduction, examining how the move categories identified are related to the contextual and epistemological characteristics of the genre.

In a second stage we will adopt a more microscopic approach, concentrating on some of the discourse's interactional features and analysing how speakers adapt their interpersonal strategies to the audience in the conference presentation setting. As Miller (1994:71) stresses, alongside recurrent structural features, genres also provide certain constraints and resources on the interpersonal level of speaker and addressee roles. We will therefore look in particular at pronoun choices and their role in creating a specific rapport with listeners. A contrastive approach will again be adopted, as a comparison with the written equivalent of the CP - the conference proceedings article (PA) - is particularly helpful in bringing out the distinctive features of the two agnate genres, and in thus highlighting the influence of the live conference environment on the language choices made.

\section{Study design}

The spoken data used for the study comprise 44 15-20 minute presentations given at international scientific conferences in three fields (geology, medicine, and physics) by native speakers. The presentations were recorded on video and then transcribed. A smaller comparative corpus composed of 13 of the physics presentations and the 13 corresponding articles published in the book of proceedings of the physics conferences (same authors, topics, and event) was also collected, to enable comparison between the presentations and proceedings articles ${ }^{\mathrm{ii}}$.

The first step was to identify the cut-off point between the introductory section and the following section in each talk. Segmenting a lengthy monologue into structural units is no easy task, as speakers rarely provide the superstructural clues that are 
materialised in the RA or that are recommended by EAP listening skills materials (Heino, Tervonen \& Tommola 2002; S. Thompson 2003). In this study, two sets of clues were used to determine the cut-off points: textual clues in the transcript, and visual clues on the video recording. Textual clues include the content itself, frame markers (Well, So, OK...), tense-shifts and structures such as pseudo-clefts (So what we decided to do was...). The visual clues were extremely helpful, as either the titles on the visuals or a shift in the type of visual shown often clearly indicated the beginning of a new section. The few dubious cases remaining were resolved by consulting specialist informants or the corresponding proceedings article, where available. The total length of the spoken data as a result is 15,639 words. For the move analysis, a dual-rating system was used throughout the process until agreement between the two analysts was reached.

\section{Contextual features of the CP}

When undertaking the analysis of a genre, one is faced with an initial choice as to the approach or procedure to adopt. Askehave \& Swales propose two possible procedures: a text-driven, or linguistic approach, moving up from analysis of structure, style, content and putative purpose towards context, or on the contrary a context-driven or ethnographic procedure, moving down from investigation of the values, goals and material conditions of an identified discourse community towards specific textual features (2001:207-8). The authors acknowledge however that these procedures are "idealized and sanitized" and that the most fruitful approach is probably a combination of the two, as genre analysis is "more a matter of extensive text-in-context inquiry than straightforward textual or transcriptal scrutiny on the one hand, or introspective system building on the other" (p. 209). We subscribe to this mixed, text-in-context approach, and therefore propose, as a framework for our analysis, to briefly delineate some of the essential contextual features and functions of the CP.

In order to do this it is useful to make comparisons with agnate genres. Genres need to be positioned in relation to one another, as within a given discourse community there are a range of recognised genres which are mutually defining and constitute a system (Bazerman 1994). A brief comparison with the more widely documented research article will thus provide a relevant starting point. The CP and research article are both operated by same research community and share a certain intellectual tradition, which manifests itself in the high information load conveyed. Both are research process genres and address an esoteric public, where shared knowledge is extensive. However 
the contextual constraints governing the two events are radically different and this has an obvious impact on the precise choice of content, structure, language and semiotic resources brought into play. Among the contextual features which distinguish the two genres, four appear particularly significant:

1. In fields such as the ones studied here, which have an established journal tradition, the $\mathrm{CP}$ has a different and complementary epistemological role to play in the construction of disciplinary knowledge to that of refereed research publications Situated "midway between the embryonic, speculative claims made in the informal privacy of the lab, and the mature assertion of claims in the public rhetoric of the research article" (Rowley-Jolivet 2002:122), a major function of many conference presentations is to present work-in-progress or "proto-claims" with a high novelty value. This focus on novelty, combined with the often stringent time constraints imposed on speakers, will have a significant influence on the choice and organisation of the scientific content ${ }^{\mathrm{iii}}$.

2. The purpose of scientific research communication, whether spoken or written, is not only informative but also rhetorical in that it aims to persuade. The relationship with audience or readership is however very different in the two cases. While academic writing is "not the faceless discourse it is often assumed to be" (Hyland 1999:107), writers in hard disciplines nevertheless minimise their apparent presence in the text ( $\mathrm{p}$. 111), adopting a detached stance so as not to limit the scientific validity of the propositions. In the $\mathrm{CP}$ on the contrary, as the audience is physically present in the auditorium, it is necessary to set up a feeling of solidarity. Too detached a monologue may be ill-suited to the communicative context and appropriate interpersonal strategies are important. In setting up this relationship, the role of the introductory section is obviously a determining one.

3. The CP is, even if semi-prepared and/or rehearsed, a live event in real time. Speakers have to adapt the high-density informational content of their talks to this constraint. This has important implications for production and comprehension. The complex noun groups and nominalizations that are characteristic of the journal article are ill suited for this reason to the live $\mathrm{CP}$ environment.

4. The scientific $\mathrm{CP}$ is a multimodal genre, in which visual communication plays an enhanced role compared to its role in the RA. The importance of the visual semiotic 
means that some information may be transmitted only via the visual channel and not verbalised by the speaker (Lemke 1998; Rowley-Jolivet 2004).

All of the above features can be expected to have an impact not only on the language choices visible in the textual product but also on the structure and content of the introductions.

\section{Move analysis to explore rhetoric}

Move analysis is well-suited to investigating structure, as its principal aim is to gain insight into the communicative purpose of a discourse genre and into its specific rhetorical structure, revealed by the constituent schemata or recurrent moves, as it achieves this purpose. While Swales' (1990) revised Create A Research Space (CARS) model for research article introductions has provided an overall robust framework for capturing rhetorical structure in academic writing, its applicability to academic speech remains largely unexplored (cf. Carter-Thomas \& Rowley-Jolivet 2003).

In addition to the CARS model, we have therefore looked at two other analyses of introductions in spoken academic genres: S. Thompson's (1994) study of the introductions in university lectures, and Dubois' (1980) analysis of the genre and structure of biomedical conference presentations. By confronting these three models (Swales, Dubois and Thompson) in the light of our own data we are able to propose the move model for CP introductions shown in Figure 1. We first describe this model in the following section and then discuss the areas of overlap and divergence with the above three models, in order to bring out the specific features of the CP move structure.

\section{A move model for CP Introductions}

Three main moves were identified: Setting up the framework, Contextualising the topic, and Research rationale, with sub-moves or steps within each. In establishing the move categories, we took into account not only what the speakers said but also the information displayed on the visuals.

Insert here : Figure 1

Move A, Setting up the framework, contains two main categories, the Interpersonal framework and the Discourse framework. Within the interpersonal framework, the Listener orientation step includes all remarks addressed by the speaker to the chairperson, to the audience or the conference organisers, thanking them, greeting 
them and generally making contact. Listener orientation may of course occur at any point in the talk ${ }^{\mathrm{iv}}$, but it is particularly marked in this initial section, where certain speakers make a special effort to set up a rapport with their audience and create their persona for the presentation. It is the favoured place for jokes, personal anecdotes, and light-hearted remarks, as in the following example:

I'd like to thank all of you hardy souls for hanging out til the very end. I have the honour of presenting the last paper and I'll try to go through it fairly quickly, I know most of you are probably eager to get out to dinner and try some of the wonderful local wines here. (CP-P5)

The other recurrent step identified in the interpersonal framework is verbal and/or visual Acknowledgement of co-authors, collaborators, companies or funding agencies. These short texts are placed at the end of the RA but occur near the beginning of the CP.

I want personally to thank Dr. \{NTD\} for his spearheading this project and supplying the patients. I've always been amazed at the interest Dr. \{NTD\} has in fostering interdisciplinary types of research. I'd also like to thank Dr. $\{$ NTD $\}$ for his continued support during these studies. (CP-M14)

The Discourse framework comprises two text-oriented components, the first of which is Announcing the Topic. This seems at first sight a rather redundant step, as the chairperson has without exception just announced the speaker's topic, which is also printed in the conference programme. Its information value may therefore appear low, but its rhetorical value is high: by restating the topic, the speaker thus appropriates it, marking a clear break with the previous talk and foregrounding the new topic. Moreover, by an often slight reformulation of the topic, the speaker can highlight its interest or specificity, not always apparent from the conference title ${ }^{\mathrm{vi}}$. Note the two significant differences between the following:

Title on Conference programme

Community screening for colorectal cancer using flexible sigmoidoscopy. The Richmond experience.
Speaker's announcement of topic We'll be looking at a new way of doing community screening on the single hospital level. (CP-M3)

The second text-oriented step in the discourse framework is Outline Structure/Scope, in which the speaker indicates what aspects of the topic will or will not 
be covered, and in what depth. This outline is, in rare instances (G3), very explicit, but generally quite brief (P14):

This is the contents of my talk. I will give you an idea of the general geology, mineralization distribution in the area, definition of a highpotassium calcalkaline suite, mafic to intermediate mineralization and then the felsic mineralization associated with this and then a few conclusions. (CP-G3)

I think I will concentrate on our short pulse results and I will mention a little bit about our long pulse results. (CP-P14)

Whether brief or more extensive, all the steps in move A serve the important function of preparing the audience to receive the message, or research claim, of the talk, by generating expectations as to how the speaker will handle the communicative situation (Interpersonal framework) and by mapping out the structural contours of the talk (Discourse framework)

Once the framework has been set up, speakers start to address the scientific content of their talk by Contextualising the topic, in Move B. This is accomplished in two ways, the first of which - Conference context - is specific to the CP environment. The 'forum' (Porter 1992) of the conference creates a particular type of intertextuality, that of the participants' shared knowledge of the talks and discussions that have taken place at the conference itself, forming what one could call a local epistemology. This additional contextualisation component is frequently referred to by speakers, and allows them either to economize on the presentation of general background information (G6), or to show how the talk fits into the local context by complementing others already presented (P8):

This paper follows very logically on from the previous one and compliments to the organizers for that and it will save quite a lot in terms of background information. (CP-G6)

The subject of this talk is all the way from Dr. \{NTD\}'s discussion [i.e. a talk given earlier in the same session], he was trying to provide the phaser from Star Trek, we 've heard discussions just the previous talk on something that could be used perhaps with sensors. What I'm looking at is how to protect, and 'Tug on your shields, Scotty!' type of technology. (CP-P8) 
The other possible step in Move B is references to the General research context. In this step we have conflated topic generalisations and reviewing previous research, as distinguishing them even in the RA is difficult (Samraj 2002), and proved particularly problematic in the $\mathrm{CP}$ introduction. This is due to the fact that verbal references to shared knowledge are always couched in general terms and allusions to publications are non-specific:

\section{Many different techniques are known to sustain internal mode disequilibrium high pressure gases... and as you probably know, electric discharges tend to be unstable at very high pressures (CP-P19) \\ This picks up on some work the Japanese did in the middle nineties (CP- P17)}

Although a few scattered citations feature on the visuals, no instances of a full-blown literature review were encountered in the data.

Move $\mathrm{C}$, Research rationale, the final move identified in the $\mathrm{CP}$ introduction, begins with the presentation of the various Motivations that triggered the research. As in the research article, the motivation can be of several kinds, depending on the type of research undertaken. It may concern gaps in knowledge, problems with current methods and technologies, or flaws in accepted theory, leading the speaker to make a counterclaim. Alternatively, in more applied or 'world-oriented' fields, the motivation may be the perception of a practical need such as the importance of the work in terms of patient treatment, more powerful machines for industrial applications, or the detection and exploitation of mineral resources. In a few cases, the motivation for the research is that it is a follow-up or continuation of the author's previously published work in the area. Whatever the specific motivation given, this move obviously has the suasive or rhetorical aim of convincing the audience of the interest and relevance of the presentation to perceived scientific problems and needs.

The evocation of these problems and needs frequently leads to a second step, the Response, in which a possible solution to the problem is indicated. The clause-relational Problem-Response format is a productive one in our data, and underpins the rhetorical structure of many CP introductions. In the more theoretical papers, this takes the form of proposing a hypothesis or raising questions about possible approaches to the problem, while in the more applied presentations speakers even preview their main results. This aspect of the CP move structure ties in with Berkenkotter and Huckin's 
(1995) and Hyland's (2000) findings on the increase in 'promotional' features in scientific writing over the last two decades, and is discussed further below (see also Yakhontova 2003). The third step encountered in the research rationale move is the description of the precise research goal, which generally concludes the introduction.

\section{Specificity of the CP move structure}

How does the generic move model of CP introductions proposed here fit in with the other 3 reference models of academic introductions (Dubois 1980, Thompson 1994, and Swales 1990)?

Of the three, Dubois' study of the genre and structure of speeches given at a biomedical conference might be expected to display the greatest similarities to our data, as it is the only one to analyse conference presentations. Certain aspects of the structure she proposes for introductions in this genre did indeed prove insightful for our study, in particular the division between listener orientation and content orientation. The analysis was done, however, within a tagmemic typology of narrative, and proved as a result less applicable to the $\mathrm{CP}$ genre overall than the more purposeful rhetorical move analysis proposed by Swales. The narrative structure, while suited to many forms of medical discourse (Hunter 1991), meant also that certain features were too discipline-specific for a generic approach.

This drawback was not encountered with the second structural model of academic speech, S. Thompson's move analysis of lecture introductions, as her data were chosen from a range of hard and soft disciplines, precisely "to avoid any skewing of results because of possible discipline-specific factors" (1994:175). The initial function of lecture introductions identified by Thompson, Setting up the lecture framework, appeared particularly relevant to the $\mathrm{CP}$ data. Its role of providing the audience with a mental map of the lecture, through the sub-functions Announce topic, Indicate scope, and Outline structure, corresponds very closely to the Discourse framework steps in the $\mathrm{CP}$ introduction. It is worth noting, however, that indications of structure and scope tend to be brief in the $\mathrm{CP}$, as the peer audience would no doubt perceive speakers who labour these points as adopting the 'lecturer' style more suited to didactic discourse. A second similarity lies in the contextualisation strategies used by speakers. Both lecturers and conference presenters naturally refer to shared general knowledge to place their topic in context, but in addition, each individual lecture or CP forms part of a series - either previous lectures given to the same student audience, or 
previous talks presented at the conference. This local framework of shared knowledge is called on by speakers in both cases to contextualise their topic.

Major differences remain, however, between CP and lecture introductions, due to their very different audiences. The lecture is a didactic process genre addressed to novices, similar to the textbook genre in that its aim is the pedagogic one of surveying established knowledge rather than making new and possibly controversial claims (S. Thompson 1994:181). The CP, in contrast, is a research process genre aimed at convincing an esoteric and potentially hostile or sceptical audience. Consequently, the highly rhetorical Move $\mathrm{C}$ in the $\mathrm{CP}$ introductions, in which the speaker occupies a research niche by first explaining the motivation for the work then presenting the research goal or results, is absent from the lecture introductions. S. Thompson refers to the categories in her data in fact as functions and sub-functions, not moves and steps, reflecting this important difference in the communicative purpose of the two genres.

In communicative purpose, at least, the $\mathrm{CP}$ introductions bear more resemblance to the RA introductions analysed by Swales (1990). One finds in both a similar rhetorical movement from the general research context towards the specific research goal in order to provide persuasive justification for the research effort. However, the funnel effect, or rhetorical narrowing characteristic of both research process genres, is much more rapid and straight to the point in the CP. As a result, it proved difficult in practice to distinguish the two Swalesian moves Establish a Niche and Occupy the Niche in the CP, which were therefore collapsed into a single move, the Research Rationale. It also proved difficult to establish a strict ordering for the moves, due no doubt to the mixed-discipline composition of the corpus, compounded by the inherent flexibility of speech genres.

The linear representation presented in Figure 1 should not therefore be considered as rigid. Positing a strict sequence of moves even for a genre as codified as the RA can be problematic (cf. Samraj 2002). There is considerable flexibility due not only to disciplinary variation and to the specific objectives of the research, but also because of the inherent flexibility of genres themselves, which adapt in response to the evolving requirements and practices of discourse communities (Askehave \& Swales 2001; Anthony 1999). This flexibility is even more apparent in live presentations due to the sometimes impromptu decisions made by the speaker, and because the rules are far less codified. The position of Outline structure/scope would, for example, appear to be fairly freestanding. References to the General research context can occur not only 
within Move B, but later in Move $\mathrm{C}$, to reinforce the motivation for the research. The categories identified are also not mutually exclusive. Some of the talks analysed contain the majority while others only very few. There was also evidence in a small number of talks of a certain amount of 'spillage', with items from the Materials and Methods section appearing in the Introductions. Overall however the linear sequence presented can be seen to reflect the ordering of moves in the majority of CPs analysed, indicating that the $\mathrm{CP}$ introduction, like the RA, has a clear rhetorical movement.

What clearly emerges from this comparison between our data and the other move-based studies is that $\mathrm{CP}$ introductions, though related in certain aspects to introductions in other academic genres, form their own combination of features, creating a fresh synthesis which has a genre-specific structure. On the one hand, they share with lectures a similar communicative format - the oral delivery of a lengthy expository monologue to a real audience - leading in both to the setting up of an interpersonal and cognitive framework for the discourse. On the other hand, the audience and global rhetorical purpose of the $\mathrm{CP}$ are closer to those of the RA. The CP introduction is weighted differently, however, with some features prominent in the RA introduction being downplayed in the $\mathrm{CP}$, while others are fronted.

The features we wish to highlight are audience- and context-related, as these clearly distinguish the $\mathrm{CP}$ introduction from that of the RA. The presence of a live audience, who will engage in a direct dialogue with the speaker during the discussion phase after the presentation, means that speakers need to explicitly acknowledge the role of these co-enunciators of the presentation event considered as a whole. As much recent work on academic writing has stressed, this interactional dimension is also present in written genres, where audience awareness and the construction by writers of a reader-in-the-text is an important feature of persuasion (e.g. G. Thompson 2001; Hyland 1999). It is however incomparably more overt and on the textual surface in the CP than in the corresponding article, as the following section demonstrates. It is also far more local or targetted in its realisation, as the many exophoric references to the conference environment of the talk attest - the speaker has to deal with a real, or actual, audience, not an ideal one. Setting up the interpersonal relation with the audience is therefore an important rhetorical move in the CP.

Another prominent function of the $\mathrm{CP}$ introduction is to provide the audience with an interpretive framework for the subsequent discourse. The cognitive burden of processing a heavy information load in real time makes it very helpful to give the 
audience advance signalling of the topic and organisation of the talk. This is the role of the setting up the Discourse framework step. This step is, moreover, frequently positioned near the beginning of the introduction rather than at the end as in RA introductions.

Not only the audience but also the speaker are present in person during a conference presentation. The speaker's persona - defined as the "created personality put forth in the act of communicating" (Campbell 1975:394) - is established by strategies that are very different from those of the RA. Non technical arguments are an important means of persuasion in conference presentations: speakers "radiate equanimity and goodwill" and engage in "mild, easy humor, usually (...) before the serious, or scientific portion of the speech" (Dubois 1981:405-6). This projection of a courteous, friendly image is achieved through the Listener orientation step, while speaker modesty is reflected in the Acknowledgements step. As Giannoni (2002) notes, the prevalence of Acknowledgements in present-day RAs reflects the increasingly collaborative environment of research, but in the $\mathrm{CP}$, their other function as a politeness strategy would seem equally important. As the presentation is delivered by a single speaker but the research is a collective effort, the explicit acknowledgement of others' collaboration contributes to creating the persona of "the presenter as modest expert" (S. Thompson 1997).

A further specific feature of $\mathrm{CP}$ introductions that is related to the communicative context concerns the manner in which the research topic is contextualised. In almost half the CPs analysed, speakers situate their topic by referring to other presentations or events (e.g. posters) at the conference. This can be seen as indicative of the importance of conferences as fora for disciplinary interaction and discourse community cohesion. The local epistemology of the conference creates a micro-context that is immediately relevant for the audience attending the talk.

In contrast, contextualisation of the topic by a canonical literature review, such as that found in the RA, is apparently considered by participants to be unnecessary or unsuited to the CP. Clearly, time constraints in the CP partly explain why a full literature review is not feasible, but this also reflects the different epistemological function of the CP. What conference participants come to hear are the latest results "hot off the press data" in the words of one of the speakers in the corpus - and the novelty or news value has to be high. As a result, the amount of time devoted to shared background knowledge is curtailed. Moreover, the very allusive references to previous 
research that are made verbally show that in oral communication the elaborate, conventionalised citation practices of writing are largely irrelevant.

The mixed-disciplinary corpus used in this study means that only very broad generic differences between the move structure of the CP and RA introductions can be proposed. A more detailed analysis, focusing on individual disciplines, remains to be done and would doubtless enable refinements to be made to the model. Some important distinctions can however be made concerning the recurrent moves in the $\mathrm{CP}$ compared to the RA. The highly-preferred steps, which occur in the majority of the CPs, are:

\section{Listener orientation (A. 1a)}

Announce topic (A.2a),

General research context (B. 1b),

Outline research goal (C.3).

These preferred steps reflect the three main moves (A, B, and C) that we have distinguished and the above sequence could thus perhaps be considered as presenting a minimum skeletal structure, or default option, for the conference presentation. It is interesting to note that of these four highly preferred categories, two are specifically related to the CP environment: Listener orientation (interpersonal relations) and Announce topic (foregrounding the individual presentation within the conference setting), showing once again the importance of modal and contextual influences.

Move analysis has allowed us to highlight those differences in argument structure between $\mathrm{CP}$ and research article introductions that are motivated by the interactional context of the CP genre. The other important aspect of interaction we wish to address concerns the interpersonal relations set up by the allocation of speaker and addressee roles through the use of personal pronouns. As S. Thompson (1997) demonstrates, speakers' choices here also depend on the communicative goals of a genre, in particular on whether to draw the audience into the textual world or not.

\section{Speaker and Addressee Roles}

We focus on the use and distribution of subject pronouns, as their role in establishing the speaker and addressee roles is particularly important. In order to bring out certain distinctive features of pronoun use in the CP introductions a comparison with the written equivalent of the $\mathrm{CP}$ - the conference proceedings article (PA) - proves insightful (see also Vassileva 2003). 
Insert here : Table 1. Subject pronouns in Conference Presentation (CP) and Proceedings Article (PA) Introductions.

As can be seen from the above table, subject pronouns as a general category are far more widely used in the CP introductions with 201 occurrences in the $13 \mathrm{CP}$ introductions (representing $48 \%$ of clausal subjects) and only 29 (11\% of clausal subjects) in the corresponding PA introductions. If we consider the total number of personal pronoun subjects in the two corpora the figures are even more striking - $40 \%$ of clausal subjects in the CP are personal pronouns, as against only $5.2 \%$ in the PA. In our data, the only personal pronoun to be used with any frequency in the PA introductions is we, and the personal pronouns $I$ and you are absent altogether from the PA. The absence of $I$ is due to the fact that all the physics articles are multi-authored.

The greater recourse to pronouns in general in the CP can firstly be directly related to certain contextual constraints of the CP environment. Speakers have to adapt the high informational content of their talks to live delivery, and the complex nominal subject groups characteristic of scientific writing are both difficult to produce and understand in real time. Shorter clauses and initially placed pronoun subjects facilitate however real time processing ${ }^{\text {vii }}$.

This contextual constraint has a marked impact on the frequency of two syntactic structures commonly found in scientific writing, the passive and extraposition. Traditionally the passive has been considered as one of the principal means of achieving impersonality and distance in a text, as it enables the removal of any explicit agency (Chafe 1982). In the PA introductions, agentless passives are numerous:

Narrow beams of nanoparticles can be used (PA-P16)

Two sets of experiments are described (PA-P11)

In the $\mathrm{CP}$, on the other hand, such passive constructions are rare; speakers prefer to express actions and opinions congruently, taking full responsibility and even underlining their participation in the research projects:

We use a carbon dioxide laser (CP-P19)

I have put together a low voltage hundred-kilowatt repetitive source (CPP13)

Considerations relating to author responsibility can also explain why structures involving extraposition are also less frequently found in the CP. In their writing scientists often use extraposition as a hedging tactic (Hyland 1998; Hewings \& Hewings 
2002), as it provides a grammatical framework for expressing stance or evaluation while at the same time, like the passive, respecting the impersonal tone commonly found in the scientific article. Witness for example the following in PA introductions:

It is well known that ferroelectric ceramics have relative dielectric constants (PA-P4)

It is shown that these Blumlein pulsers can be developed into light and compact devices (PA-P3)

Instead of using an extraposed clause, introduced by a semantically empty $I t$, conference speakers tend to express their evaluation and comments far more openly, using personal pronouns - we know, we want, we can, I believe etc. - with hedging accomplished by subjective comment clauses (I think that...) rather than by the more impersonal or objective modalisation of extraposition:

We just want to see how fast we can make it, as fast as possible really (CP-P4)

We can't take the voltage down significantly. (CP-P9)

I think our new understanding that has arisen over the last year or so, I guess independently in our group and in Tomsk, is that ... (CP-P14)

The conference speaker's choice to adopt more pro-active communicative strategies, orienting clauses around personal pronouns and active verbs creates a very different atmosphere to that of the article. As Hyland has shown, writers in science and engineering are reluctant to project a prominent authorial presence, and this was interpreted as indicative of differing textual practices along the hard/soft disciplinary divide (1999:115). Our CP data show, however, that while this disciplinary difference may hold true for writing, it is erased in speech, where the influence of the oral mode and communicative context lead speakers even in hard disciplines to take a discoursal stance characterised by a higher degree of personal involvement.

This emerges clearly when one takes a closer look at the distribution of the three pronouns we, $I$ and you in the two genres. In the PA, the 'objective' wisdom of the author(s) is expressed through impersonal formulations and very occasionally, as can be seen from Table 1, in collective terms by an exclusive we (referring to the co-authors of the article). There is however no inclusive use of we (referring to both authors and readers). All the occurrences of we found in the PA corpus correspond uniquely to a collective authorship and primarily occur where authors outline their research aims:

We would like to produce energetic neutrals. (PA-P17) 
We seek analytically to discover 'interesting' solutions such as solitary waves. (PA-P15)

In the $\mathrm{CP}$ corpus the pronoun we is however used both with exclusive and inclusive values. When we is used with its exclusive value it is often to recount the different actions of the research team. Accompanied by the present perfect the ongoing nature of the research work is thus emphasised.

We've gone on to stack the blumleins (CP-P3)

We 've been able to vary the voltage (CP-P9)

The pronoun we is also used however with a more inclusive value:

I'll also say a little bit about ...the sort of efficiencies we can expect from these various configurations (CP-P11)

... maybe we need to stop thinking about these devices as classical devices (CP-P14)

In this way the conference speaker interacts with the listeners, signalling disciplinary solidarity by involving them in the research choices and decisions.

As table 1 demonstrates, the $1^{\text {st }}$ person pronoun $I$ is also frequent in the $\mathrm{CP}$ corpus. The speaker's authority is thus established on very different grounds to that in the PA, with rhetorical persuasion relying on his ability to evoke a real person in the text having sufficient confidence in his personal qualities to use $I$. In many instances the $I$ is part of a metatextual strategy, in which, when combined with the future simple tense, the speaker signposts the organisation of his talk for listeners as part of the Outline structure or scope step:

My talk today on...has three objectives. The first, I'll look at a simple axisymmetric Milo configuration,.... I'll then go on to .... And I'll also throughout the talk ....(CP-P11)

I will say a few words about our long pulse experiments and I will give you my opinion about the future prospects in this area (CP-P14)

On other occasions the speaker uses the first person singular to underline his personal involvement in the research project:

I found it's very difficult to turn on ......and so I launched off into a little study... (CP-P13),

to underline the importance of the issue raised:

And that is one point I hope you go away with (CP-P14), 
or to give overt expression to a personal affect :

We call the first one SNIPER, which is an acronym that I'm very proud of. (CP-P2)

There are however no occurrences of $I$ in the PA. As Hyland (2001) has shown in a cross-disciplinary comparison of self-mention in the research article, the first person singular is never used in hard scientific disciplines such as physics and engineering though it is relatively frequent in disciplines such as philosophy. Our physics PA data not only corroborate this finding, but also extend it to the singular personal pronoun you, which is likewise absent in the PA introductions.

The personal pronoun you features however prominently in the CP introductions, where it can be seen to have several different values. It refers firstly to the scientific community at large, and would in many cases be expressed by an impersonal structure in the article:

Laser excitation is not very efficient especially if you have to use multi photon excitation (CP-P19)

.. the sheath is so thin you don't have room to do neutralisation (CP-P17)

On other occasions however the speaker appeals directly to the listeners in the auditorium, emphasising their shared knowledge of the subject:

As you probably know electric charges tend to be unstable ...(CP-P19)

You know that plasma can very well generate nanoparticles. It's however difficult...(CP-P16)

The pronoun you is also used to direct the audience's attention to the visual information displayed on an overhead in the shared conference environment:

As you can see the volume is reduced by over an order of magnitude(CP-P5)

They've been around, as you see here, since around world war two (CPP14)

For major portions of the talk, the visual display is in fact the common focus of attention for both speaker and audience, as many aspects of scientific phenomena can only be communicated visually. These graphic representations recreate in $2 \mathrm{D}$ on the slide the laboratory experience shared by all the participants. When you is used to comment on such visuals, it appears to have the value of 'you and me as experimentalists' as it allows the speaker to recreate, often quite vividly, the experimental conditions of the lab: 
you have a certain state or a certain mode in a molecule or in an atom that you want to excite and what you do is you shine a laser into the gas, you excite that state, but as you can see collisions especially at high pressures tend to depopulate the state...(CP-P19)

The speaker draws the audience into the research process, attributing to them the role of joint researchers, in a similar way as with the inclusive we discussed earlier. This fully supports similar observations on interaction in scientific conference presentations, as compared to presentations in linguistics (S. Thompson 1997), and would seem to be a domain-specific feature of the genre.

On occasion, you refers neither to the speaker nor to the audience, but to an inanimate entity with which they both identify, such as ions in the following example:

when the velocity is equal to the sound speed, you're at the sheath edge and quasi-neutrality breaks down (CP-P17)

The distinction between speaker and audience gives place to a "blended identity", confirming the interesting observation made by Ochs, Gonzales and Jacoby (1996:330) in their study of research presentations in a physics lab:

scientists express their subjective involvement not only by foregrounding their role as practitioners of scientific activity, they also express involvement more extremely by taking the perspective of (empathizing with) some object being analyzed and by involving themselves in graphic (re)enactments of physical events.

This use of you is further evidence of the close connection between laboratory life and talk, and the conference presentation, discussed in greater detail elsewhere (RowleyJolivet 2002).

The study of personal pronoun use and distribution does not of course exhaust all the interpersonally-oriented interactional features observable on the textual surface. Two other interesting syntactic choices which contribute to creating speaker-audience interaction are direct or implied questioning procedures such as rhetorical questions and $W h$-clefts ${ }^{\text {viii }}$. Both are considerably more frequent in the CP data than in the corresponding PAs, and both set up a fictionalised dialogue between the participants. For reasons of space, however, these cannot be examined here.

\section{Conclusion}


Much of the recent work on the rhetoric of academic discourse has focused on written genres. In this study, we have attempted to analyse an academic speech genre from a rhetorical perspective. We have seen how the means of securing persuasion - the fundamental aim of rhetoric - are closely linked to the contextual constraints and purposes of the CP genre. Speakers are aware of the difficulty for their audience of processing in real time a lengthy spoken monologue with a heavy information load, and adapt both their argument and the allocation of roles accordingly.

On the level of argument, the move analysis of the CP introductions has shown, for example, that speakers set up a discourse framework to facilitate interpretation of the talk, and contextualise their topic not by a canonical literature review - which would be extremely hard to process in real time - but by more local references and by relying on the extensive shared knowledge of the peer audience. The particular epistemological purpose of the $\mathrm{CP}$ also impacts on argument structure, resulting in a stress on novelty and results rather than on background information. The presence of the live audience leads to further differences in rhetorical structure compared to the RA, as speakers devote space and time in their introductions to setting up an interpersonal framework and creating their persona of a modest, co-operative fellow-researcher.

A similar concern for a contextually-adapted rhetoric is visible in the roles that speakers allocate to themselves and to the audience. By using shorter clauses and congruent verb structures, rather than passives and extraposition for example, speakers not only facilitate information processing for the audience but also evaluate their statements in a more suitably interactive way. The live environment also leads speakers to discard the distanced, impersonal participant roles of the RA in favour of an overt engagement or involvement in the research decisions and actions presented, expressed by the high frequency of $I$ and we pronouns. Perhaps the most striking influence of the context on participant roles, however, is shown in the very widespread use of the pronoun you, attributing the role of fellow researchers to the listeners and involving them actively in the research process. The common focus of attention for both speakers and audience on the visual display is, we would contend, one of the main contextual means by which this joint, even if virtual, research participation is brought about.

The stringent time constraints imposed at scientific conferences mean that speakers need to create an atmosphere conducive to the effective transmission of the discourse from the outset. The role of the introduction in setting up a rhetorically appropriate framework in response to the contextual and epistemological requirements 
of the genre is thus crucial. We believe that the results presented here can also provide a useful corrective to any tendency, based solely on the analysis of written scientific discourse, to reifying the impartial, distanced rhetoric of science. If one wants to use genre analysis to teach learners how to adapt their discourse in a way that is appropriate to the context, then the model used must reflect the common practice of the discourse community in question - and in the case of the $\mathrm{CP}$ use for example the appropriate argumentative and politeness strategies. The role of the speaker at the outset of the presentation is both interpersonal and cognitive, and neglecting either of these roles may have a negative impact on the rhetorical efficacy of the talk as a whole

It remains to be seen, however, to what extent some of the features described in this study are language- or culture-specific. Although several analysts have recently pointed out a global trend towards a more conversational discourse style in institutional texts (Gotti 2004), the interactive and relatively informal style of presentation adopted by the native English speakers in our sample may be considered, in many European academic cultures, to be inappropriate for spoken academic communication - and may even be resisted if it is felt to imply the importation, along with the English language, of alien discourse norms. In addition, speakers of other languages may be less familiar with spoken than with written English and the possibility of culturally or linguisticbased variety or difference would thus appear potentially much greater than in the case of the highly codified research article. This study has hopefully pinpointed the salient characteristics of native-speaker introductions in science, and it will therefore be interesting now to investigate possible variants or differences - either in rhetorical structure, audience interaction, or language use - linked to the presenter's native language and culture.

\section{Appendix 1}

The spoken data used in this study comprise 44 oral presentations given by NS at the following conferences:

1. EUG VII : European Union of Geosciences, 4-8 April 1993, Strasbourg.

2. International Symposium on Mineralization related to Mafic and Ultramafic Rocks, 1-3 Sept. 1993, Orleans.

3. First International Symposium on Conservative Treatment in Oncology, 17-19 June 1993, Lyon.

4. First Annual European-American Conference on Gastrointestinal Oncology : Cancers of the Lower Gastrointestinal Tract, 22-24 Sept. 1994, Bordeaux. 
5. Euro Electromagnetics. International Symposium on Electromagnetic Environments and Consequences. May 30 - June 4, 1994, Bordeaux.

6. $15^{\text {th }}$ International Symposium on Plasma Chemistry (ISPC 15). Orléans, 9-13 July 2001.

The comparative corpus of 13 proceedings articles (PA) +13 presentations $(\mathrm{CP})$ in physics (from conferences $\mathrm{N}^{\circ} 5 \& 6$ above) comprises the following :

PA2 - CP2 Sandia National Laboratories' high power electromagnetic impulse sources.

PA3 - CP3 Stacked Blumlein pulse generators: versatile sources of high power repetitive waveforms.

PA4 - CP4 High voltage pulse sharpening using nonlinear ferroelectric ceramic dielectrics.

PA5 - CP5 Lightweight, tactical prime power for mobile pulsed power applications.

PA9 - CP9 The development of high peak power solid state pulse generators.

PA11 - CP11 Milo experiments and computer simulations.

PA13 - CP13 Low-voltage, explosive whisker emission cathode studies.

PA14-CP14 Efficiency enhancement of high power vacuum backward-wave oscillators driven by short pulse and long pulse electron beams.

PA15- CP15 Nonlinear space-charge waves in an axially uniform waveguiding structure.

PA16 - CP16 Focused beam deposition of plasma-synthesized nanoparticles.

PA17 - CP17 Theory and preliminary design of a neutral etcher based on an ECR plasma.

PA18 - CP18 Modeling of a transferred-arc metal evaporator.

PA19 - CP19 RF energy coupling to atmospheric pressure nonequilibrium plasmas.

\section{References}

Anthony, L. (1999) Writing research article introductions on software engineering: How accurate is a standard model? IEEE Transactions on Professional Communication Vol. 42 (1):38-45.

Askehave, I. \& J.M. Swales. (2001) Genre identification and communicative purpose: A problem and a possible solution. Applied Linguistics 22(2):195-212.

Atkinson, D. (1999) Scientific discourse in sociohistorical context: The Philosophical Transactions of the Royal Society of London, 1675-1975. Mahwah, NJ: Lawrence Erlbaum.

Bazerman, C. (1994) System of genres and the enactment of social intention. In A. Freedman \& P. Medway, Genre and the new rhetoric. London: Taylor \& Francis. 79-101.

-- (1998) Shaping written knowledge: The genre and activity of the experimental research article in science. Madison: University of Wisconsin Press.

Berkenkotter, C. \& T. Huckin. (1995) Genre knowledge in disciplinary communication. Hillsdale, NJ: Lawrence Erlbaum.

Biber, D., S. Johansson, G. Leech, S. Conrad \& E. Finegan. (1999) Longman grammar of spoken and written English. Harlow, Pearson Education Limited.

Biber, D., R. Reppen, V. Clark \& J. Walter. (2001) Representing spoken language in university settings: The design and construction of the spoken component of the T2K-SWAL corpus. In R.C. Simpson \& J.M. Swales, Corpus linguistics in North America. 48-57.

Burgess, S. (2002) Packed houses and intimate gatherings: Audience and rhetorical structure. In J. Flowerdew, Academic discourse. London: Pearson Education. 196-215.

Campbell, P.N. (1975) The personae of scientific discourse. Quarterly Journal of Speech 61:391-406. 
Carter-Thomas, S. \& Rowley-Jolivet, E. (2003) Analysing the scientific conference presentation (CP). A methodological overview of a multimodal genre. $A S p$, La Revue du GERAS, N 39-40: 59-72.

Chafe, W. (1982). Integration and involvement in speaking, writing and oral literature In D. Tannen. Spoken and written language: exploring orality and literacy. Norwood, NJ: Ablex. 35-53

Cmerjkova, S. (1996) Academic Writing in Czech and English. In E. Ventola \& A Mauranen (eds): Academic writing. Intercultural and textual issues. Amsterdam/Philadelphia: John Benjamins. 137-153.

Crookes, G. (1986) Towards a validated analysis of scientific text structure. Applied Linguistics 7 (1):57-70.

Dubois, B.L. (1980) Genre and structure of biomedical speeches. Forum Linguisticum $\mathrm{V}: 140-168$

-- (1981) Nontechnical arguments in biomedical speeches. Perspectives in Biology and Medicine Spring:399-410.

Dudley-Evans, T. (1994) Genre analysis: an approach to text analysis for ESP. In M. Coulthard, Advances in written text analysis. London: Routledge. 219-228.

Fløttum, K. (forthcoming) The self and the others - polyphonic visibility in research articles. International Journal of Applied Linguistics.

Flowerdew, J. (ed.) (1994) Academic listening: Research perspectives. Cambridge: Cambridge University Press.

Freedman, A. \& P. Medway. (eds) (1994) Genre and the new rhetoric. London: Taylor and Francis.

Giannoni, D.S. (2002) Worlds of gratitude: A contrastive study of acknowledgement texts in English and Italian research articles. Applied Linguistics 23(1):1-31.

Gotti, M. (2004) English in intercultural settings: Globalising trends and local resistance. Paper presented at the conference Identity, Community, Discourse: English in Intercultural settings, University of Turin, 30 Sept.-2 Oct. 2004.

Heino, A. E. Tervonen \& J. Tommola. (2002) Metadiscourse in academic conference presentations. In E. Ventola et al, The Language of conferencing. 127-146.

Hewings, M \& A. Hewings. (2002) 'It is interesting to note that...': a comparative study of anticipatory it in student and published writing. English for Specific Purposes 21:367-383.

Hunston, S. (1989) Evaluation in experimental research articles. Unpublished $\mathrm{PhD}$ Thesis, University of Birmingham.

Hunter, K.M. (1991) Doctors' stories: The narrative structure of medical knowledge. Princeton, NJ: Princeton University Press.

Hyland, K. (1998) Hedging in scientific research articles. Amsterdam: John Benjamins.

-- (1999) Disciplinary discourses: writer stance in research articles. In C.N. Candlin \&

K.Hyland. Writing: texts, processes and practices. London: Longman. 99-122.

-- (2000) Disciplinary discourses. Social interactions in academic writing. London: Longman.

-- (2001) Humble servants of the discipline? Self-mention in research articles. English for Specific Purposes 20:207-226.

Lemke, J. (1998) Multiplying meaning: Visual and verbal semiotics in scientific text. In J.R. Martin \& R. Veel. Reading science. London: Routledge. 87-113.

Mauranen, A. (2001) Reflexive academic talk: Observations from Micase. In R.C. Simpson \& J.M. Swales. Corpus linguistics in North America. 165-178.

MICASE. http://www.hti.umich.edu/m/micase. Michigan Corpus of Academic Spoken English. 
Miller, C. (1994) Rhetorical community: the cultural basis of genre. In A. Freedman \& P. Medway, Genre and the new rhetoric. 67-78.

Montgomery, Scott L. (1996) The scientific voice. New York: Guilford Press

Nwogu, K. (1997) The medical research paper: Structure and functions. English for Specific Purposes 16 (2):119-138.

Ochs, E., P. Gonzales \& S. Jacoby. (1996) 'When I come down I'm in the domain state': grammar and graphic representation in the interpretive activity of physicists. In E. Ochs, E. Schegloff \& S.A. Thompson, Interaction and grammar. New York: Cambridge University Press. 328-369.

Porter, J.E. (1992) Audience and rhetoric: An archaeological composition of the discourse community. Englewood Cliffs, New Jersey: Prentice-Hall.

Räisänen, C. (2002) The conference forum: a system of interrelated genres and discursive practices. In E. Ventola et al, The language of conferencing. 69-93.

Rowley-Jolivet, E. (2002) Science in the making: Scientific conference presentations and the construction of facts. In E. Ventola et al, The Language of conferencing. 95-125.

-- (2004) Different visions, different visuals. A social semiotic analysis of field-specific visual composition in scientific conference presentations. visual communication 3 (2), Sage.

Rowley-Jolivet, E. \& S. Carter-Thomas. (in press) Genre awareness and rhetorical appropriacy: manipulation of information structure by NS and NNS scientists in the international conference setting. English for Specific Purposes.

Samraj, B. (2002) Introductions in research articles: variations across disciplines. English for Specific Purposes 21(1):1-17.

Shalom, C. (2002) The academic conference: A forum for enacting genre knowledge. In E. Ventola et al, The language of conferencing. 51-68.

Simpson, R.C. \& J.M. Swales. (eds) (2001) Corpus linguistics in North America. AnnArbor: University of Michigan Press.

Swales, J. (1981) Aspects of article introductions. Birmingham: The University of Aston, Language Studies Unit.

-- (1990) Genre analysis. Cambridge: Cambridge University Press.

-- (2003) That master narrative of our time: The research article revisited. Keynote speech at the $14^{\text {th }}$ European Symposium on Language for Special Purposes, University of Guildford, 18-22 August, 2003.

Taylor, G \& T. Chen. (1991) Linguistic, cultural and subcultural issues in contrastive discourse analysis: Anglo-American and Chinese scientific texts. Applied Linguistics 12/3:319-336.

Thompson, G. (2001) Interaction in academic writing: Learning to argue with the reader. Applied Linguistics 22(1):58-78.

Thompson, S. (1994) Frameworks and Contexts: A Genre-based approach to analysing lecture introductions. English for Specific Purposes 13(2):171-186.

-- (1997) Presenting research: A study of interaction in academic monologue. Unpublished $\mathrm{PhD}$ Thesis. Liverpool: University of Liverpool.

-- (2003) Text-structuring metadiscourse, intonation and the signalling of organisation in academic lectures. Journal of English for Academic Purposes 2:5-20

Tracy, K. (1997) Colloquium: dilemmas of academic discourse. Norwood, NJ: Ablex.

Valle, E. (1999) Collective intelligence: the life sciences in the Royal Society as a scientific discourse community, 1665-1965. University of Turku, Finland.

Vassileva, I. (2003) Englisch und Deutsch als internationale Konferenzsprachen: Sprecher-Zuhörer-Interaktion. Fachsprache / Special Languages 1-2, 35-46. 
Ventola, E, C. Shalom, \& S. Thompson. (eds.) (2002) The language of conferencing. Frankfurt am Main: Peter Lang.

Yakhontova, T. (2003) Cultural variation in academic discourse: the issue of influencing factors. Paper presented at the $14^{\text {th }}$ European Symposium on Language for Special Purposes, University of Guildford, 18-22 August, 2003. 


\section{A. Setting Up the Framework}

$\begin{array}{rrl}\begin{array}{r}\text { Interpersonal framework } \\ \text { and/or }\end{array} & \text { la } & \begin{array}{l}\text { Listener orientation } \\ \text { Acknowledgements }\end{array} \\ \text { Discourse framework } & \text { 2a } & \text { Announce Topic } \\ \text { and/or } & \text { 2b } & \text { Outline Structure/Indicate Scope }\end{array}$

B. Contextualising the Topic

1a Conference context

and/or $1 b \quad$ General research context

\section{Research Rationale}
Motivation
1a Problems / Gaps / counter-claims
and/or 1b Relevance / Centrality / Need and/or 1c Continuation of previous work
Response
2a Question-raising / Hypotheses
and/or $2 b$ Preview results or solutions
3 Outline research goal

Figure 1. A move model for scientific conference presentation introductions. 


\begin{tabular}{|rrr|}
\hline & CP & PA \\
\hline I & 61 & 0 \\
\hline You & 42 & 0 \\
He & 0 & 0 \\
She & 0 & 0 \\
It & 29 & 11 \\
\hline One & 4 & 1 \\
\hline We & 58 & 12 \\
\hline They (animate) & 3 & 2 \\
\hline They (inanimate) & 4 & 3 \\
\hline Clauses with pronoun subject & $201(48 \%)$ & $29(11 \%)$ \\
\hline Clauses with animate pronoun subject & $168(40 \%)$ & $15(5.2 \%)$ \\
\hline
\end{tabular}

Table 1. Subject pronouns in Conference Presentation (CP) and Proceedings Article (PA) Introductions

\footnotetext{
${ }^{i}$ The perception of this gap has led to the creation of two corpora covering a wide range of academic speech events - MICASE (cf. Simpson \& Swales 2001) and the spoken component of T2K-SWAL (cf. Biber et al 2001) - and to studies focusing on specific events such as lectures (Flowerdew 1994) and conferences (Ventola, Shalom \& S. Thompson 2002).

ii See Appendix I for details of the corpus.

iii In the after-print fora analysed by Räisänen (2002), the CP has a somewhat different, but likewise specific, communicative role compared to written publications, that of highlighting the most salient information in the conference proceedings paper, producing a sort of promotional digest of its main findings.

${ }^{\text {iv }}$ It was excluded from her analysis on these grounds by S. Thompson (1994).

$\checkmark$ The data are referred to as follows: first CP or PA to refer to conference presentations and proceedings articles respectively, followed by a letter corresponding to the field $-\mathrm{G}$ for geology, $\mathrm{M}$ for medicine, $\mathrm{P}$ for physics - then the number of the presentation or article. See Appendix I for a complete list of the data. vi In certain cases, this reformulation of the topic is a necessity, as between the submission of the conference abstract and the presentation, last-minute changes have taken place in the focus of the research, and the title no longer corresponds to the content of the presentation.

vii For more on information-structuring principles and real-time processing, see Rowley-Jolivet \& CarterThomas (in press).

vii See Flottum (forthcoming) for an account of how the theory of polyphony can contribute to identifying other more implicit interactional features in text.
} 